See discussions, stats, and author profiles for this publication at: https://www.researchgate.net/publication/323664854

\title{
The rise of public sector innovation labs: experiments in design thinking for policy
}

Article in Policy Sciences · March 2018

Dol: 10.1007/511077-018-9315-7

\section{CITATIONS}

36

3 authors, including:

Michael Mcgann

2. National University of Ireland, Maynooth

31 PUBLICATIONS 122 CITATIONS

SEE PROFILE
4,414

Some of the authors of this publication are also working on these related projects:

Building a new research unit, The Policy Lab, at Melbourne University View project

LIPSE (EU FP7 programme) - Learning from Innovation in Public Sector Environments View project 


\title{
The rise of public sector innovation labs: experiments in design thinking for policy
}

\author{
Michael McGann ${ }^{1}$ (D) Emma Blomkamp ${ }^{2}$ (D) Jenny M. Lewis $^{2}$ (D)
}

(C) Springer Science+Business Media, LLC, part of Springer Nature 2018

\begin{abstract}
Governments are increasingly turning to public sector innovation (PSI) labs to take new approaches to policy and service design. This turn towards PSI labs, which has accelerated in more recent years, has been linked to a number of trends. These include growing interest in evidence-based policymaking and the application of 'design thinking' to policymaking, although these trends sit uncomfortably together. According to their proponents, PSI labs are helping to create a new era of experimental government and rapid experimentation in policy design. But what do these PSI labs do? How do they differ from other public sector change agents and policy actors? What approaches do they bring to addressing contemporary policymaking? And how do they relate to other developments in policy design such as the growing interest in evidence-based policy and design experiments? The rise of PSI labs has thus far received little attention from policy scientists. Focusing on the problems associated with conceptualising PSI labs and clearly situating them in the policy process, this paper provides an analysis of some of the most prominent PSI labs. It examines whether labs can be classified into distinct types, their relationship to government and other policy actors and the principal methodological practices and commitments underpinning their approach to policymaking. Throughout, the paper considers how the rise of PSI labs may challenge positivist framings of policymaking as an empirically driven decision process.
\end{abstract}

Keywords Policy design - Pubic sector innovation - Public sector reform - Policy lab · Design thinking $\cdot$ Evidence-based policymaking

Michael McGann

mmcgann@unimelb.edu.au

1 School of Social and Political Sciences, The University of Melbourne, Parkville, VIC 3010, Australia

2 The Policy Lab, School of Social and Political Sciences, The University of Melbourne, Parkville, VIC 3010, Australia 
Governments are increasingly turning to public sector innovation (PSI) $)^{1}$ labs to address the perceived shortcomings of standard approaches to policy and service design. These 'islands of experimentation' (Tõnurist et al. 2017, 8) for applying innovative methods to address public problems now include more than 60 PSI labs in European Member states alone (Fuller and Lochard 2016) although the spread of PSI labs is not confined to Europe (see, e.g. Acevedo and Dassen 2016). This global proliferation has prompted claims by their proponents that PSI labs are 'on the path to becoming a pervasive part of the social infrastructure of modern public organisations' (Carstensen and Bason 2012, 5) as governments are left with little choice 'but to innovate' (Puttick 2014, 20) in the face of increasing policy complexity and rising citizen expectations. But what do these PSI labs do? How do they differ from other public sector change agents and policy actors? What approaches do they bring to addressing contemporary policymaking? And how do they relate to other developments in policy design such as the growing interest in evidencebased policymaking?

This paper provides an analytical contribution to policy studies by examining the foundations of PSI labs and by examining their relationships to government, and their approaches and methods. It is based on an empirical analysis of the characteristics of a small number of prominent PSI labs. We also consider the type of policy design work PSI labs engage in by way of addressing their distinctiveness (or not) from other knowledge actors' (Williamson 2015a, 252). Our focus is not on whether PSI labs are effectively contributing to policymaking and public sector innovation, but instead we seek to understand whether they bring to bear a distinct modality (or logic) to policymaking and public sector innovation. Whether the ideas and proposals of PSI labs are ever enacted and implemented by decision-makers, whether they are improving policy effectiveness and whether they are a new type of actor, capable of changing the landscape of the policy process by causing a reconfiguration of policy advice, all remain important questions for future research. We begin by considering the reasons behind the recent emergence of PSI labs before turning our attention to questions about their distinctiveness.

\section{Labs and the 'problem' of public sector innovation}

The spread of PSI labs is linked to a range of factors, although a central theme within many accounts is that they are a response by governments to addressing policy problems of an increasingly 'complex and systemic' nature (Public Policy Forum 2013, 1). According to proponents of PSI labs, these range from 'reducing murder rates... and reducing poverty' (Puttick 2014, 4) to 'daunting challenges such as the global financial and economic crisis, increased social stratification, demographic change and the rise of health costs' (Carstensen and Bason 2012, 3). As Kieboom $(2014,9)$ observes, 'The latest trend in our quest to fix the global challenges of the twenty-first century is to "lab" complex issues'. What PSI labs offer in this context are seemingly 'better ways of generating new ideas' (Puttick et al. 2014, 3); in particular, through an 'experiment-oriented approach to policy design' (Fuller and Lochard 2016, 14) that draws on methods and skills usually not available in the public sector (Carstensen and Bason 2012, 5).

\footnotetext{
1 We use the term public sector innovation (PSI) lab to refer to the related concepts of 'public policy' and 'public innovation' labs.
} 
Of course, the 'problem' of public sector innovation is not new. Indeed, the emergence of PSI labs follows on directly from previous public sector innovation discourses (Tõnurist et al. 2017, 2) and earlier reform attempts such as the 'reinventing government' (Osborne and Gaebler 1992) reforms, and more broadly, the New Public Management (NPM) ideas that started to spread in many nations in the 1980s. For example, well over 200 'reinvention laboratories' were established within US Federal Government agencies under the Clinton administration in order to find ways of making government more efficient (Thompson and Ingraham 1996). This was part of a broader attempt to institutionalise a more 'entrepreneurial' state, driven by the perception that public sector bureaucracies were resistant to change and 'unable to deal with new challenges' (Saint-Martin 2001, 578).

Drawing on organisational theory and reflecting a Schumpeterian paradigm which sees competition and the pursuit of profitability as the catalysts of innovation (Potts and Kastelle 2010), NPM ideas advanced a more entrepreneurial public sector characterised by the adoption of private sector management practices and market competition in the delivery of public services (Hood 1991). One manifestation of this was an expanding 'knowledgefor-policy market' (Hart and Vromen 2008, 143) in countries such as the USA, Canada and Britain (among others) as consultants became increasingly important producers and suppliers of knowledge about 'how to inject competition' (Saint-Martin 2001, 595) into the public sector. This externalisation of policy advice was partly justified on the basis of the increased complexity of policy challenges and the perception that this further reduced the policy capabilities of the public sector (Craft and Howlett 2013, 190). This is a themeechoed in more recent justifications of PSI labs, with advocates such as Carstensen and Bason claiming that traditional public sector organisations lack the capabilities and skills 'to develop the radical new solutions that are needed' $(2012,3)$ due to their bureaucratic structure. Bureaucracies bring 'predictability and order' (Puttick et al. 2014, 3), but this emphasis on stability fosters an organisational culture that is risk averse and resistant to experimentation (Schuurman and Tõnurist 2017, 7). As a result, public sector organisations tend to favour incremental over radical or systemic changes, a propensity that is further intensified by their accountability to office holders and the associated political and media scrutiny that they are under (John 2014). Underpinning this critique of public sector bureaucracies is the (contestable) assumption that innovation is necessarily disruptive rather than gradual; contingent on capabilities for 'divergent thinking' (Torjman 2012, 6).

This raises the question: What distinguishes PSI labs from earlier agents of public sector reform such as reinventing government labs or the 'hidden public service' (Craft and Howlett 2013, 188) of policy consultants? Relatively little according to critical commentators, who view the proliferation of PSI as simply the latest fad in agencification (Tonurist et al. 2015,6) and symptomatic of the NPM trend towards displacing responsibilities onto 'a messy patchwork of outsourced providers' (Williamson 2015a, 253). But we suggest that one important difference is their emphasis on applying a 'design thinking' approach.

The emergence of PSI labs has been associated with various policy trends, including growing interest in evidence-based policymaking (Fuller and Lochard 2016) and the pursuit of 'open government' agendas (Acevedo and Dassen 2016) to foster trust and transparency through making publicly held data more accessible beyond government organisations (Yu and Robinson 2012, 192). Nevertheless, the application of 'design thinking' approaches to public policymaking remains a focal concern of many PSI labs, with some proponents going so far as to suggest that the role of PSI labs is 'to create motivation and commitment to design thinking for policymaking' (Mintrom and Luetjens 2016, 400). This interest in applying design thinking to policy has coincided with a 'social turn' (Chen et al. 2016) within the field of design, as designers have sought to evolve design 
beyond a craft-based discipline focused on product design into a framework for developing more participatory and cross-disciplinary approaches to social problems (Torjman 2012). Whereas NPM spawned an entrepreneurial mode of governance that emphasises market competition and corporate management (Considine and Lewis 2003), design thinking purportedly shifts public managers 'towards a more networked and inclusive model of service provision' (Bason 2013, viii). Within the literature on PSI labs, 'design' is frequently portrayed 'as a tool that elicits active participation from the community' (Torjman 2012, 7) so as to enable 'more nuanced solutions' (Mintrom and Luetjens 2016, 392) through the richer understanding that is gained by involving citizens and other end users in reframing problems and in ideating solutions (Rebolledo 2016, 44). While labs differ in the extent to which they meaningfully engage non-traditional policy actors in this process, their application of design thinking invites a more diverse range of voices and inputs into the policy process that resonates with principles of network governance (Considine and Lewis 2003) and, more recently, co-production (Voorberg et al. 2015). It also aligns with 'negotiated' and 'relational' approaches to problem-solving in interconnected domains where simple technical solutions may not be feasible or apparent (Head 2008, 4).

Thus far, PSI labs have received little attention within either the policy sciences or public management literature. Beyond case studies written by practitioners, the existing literature on PSI labs mainly consists of a series of overviews and practice guides produced by pioneering organisations such as the UK innovation charity, Nesta (formerly the National Endowment for Science, Technology and the Arts) (Puttick 2014; Puttick et al. 2014), the Design for Social Innovation and Sustainability (DESIS) Network (Selloni and Staszowski 2013), La 27e Région (Fuller and Lochard 2016) and MaRS Solutions Lab (Torjman 2012). It is only recently that academic working papers (Gryszkiewicz et al. 2016; Tõnurist et al. 2015; Williamson 2015b) and journal articles (Schuurman and Tõnurist 2017; Tõnurist et al. 2017; Williamson 2015a) on PSI labs have begun to emerge.

Our paper provides a first step in understanding the place of PSI labs in policy systems. We begin by outlining the many labels and meanings of PSI labs within the literature and consider how they might fit within the broader landscape of policy institutions and processes. We then sample a number of prominent PSI labs and, based on publicly available information, classify them based on their relationship to government and their dominant approaches and methods. We conclude with a consideration of their relationship to the policy process and provide some thoughts on a range of seemingly fruitful research directions on labs as a new type of actor in the policy process.

\section{What is a PSI lab?}

Writing about 'social innovation' and 'co-creation' as new reform strategies, Voorberg et al. $(2015,1334)$ suggest that these are examples of what Politt and Hupe call 'magic concepts': concepts that are 'very broad, normatively charged, and lay claim to universal or near universal-application' (Pollitt and Hupe 2011, 643). Jenson and Harrisson (2013, 14) likewise characterise 'social innovation' as a 'quasi-concept': there is little agreement about its definition although this indeterminacy makes it highly adaptable to the shifting contours of policy directions and challenges. The concept of a PSI lab has a similarly 'indeterminate quality' (Jenson and Harrisson 2013, 15) in that there is little agreement over what PSI labs actually are despite repeated observations that they are rapidly spreading (Kieboom 2014; Williamson 2015b). This is not helped by the multitude of terms used to refer to the 
same labs. To take a prominent example, the Danish Government's MindLab has variously been described as an innovation unit or i-team (Puttick et al. 2014), an i-lab (Tõnurist et al. 2017), a public policy lab (Fuller and Lochard 2016), a government innovation lab (Selloni and Staszowski 2013), a change lab (Public Policy Forum 2013; Torjman 2012), a design lab (Torjman 2012) and a social innovation lab (Kieboom 2014). The latter three terms are particularly indeterminate categories that incorporate organisations that often have little to do with policy innovation. For instance, Amsterdam's Slow Research Lab-a platform to 'investigate an expanded terrain of individual and collective potential that brings balance to the pace at which we encounter the world' ('Slow Research Lab' 2016) —is featured alongside MindLab in one overview of design/change labs (Torjman 2012,11).

We use the acronym PSI lab to refer to labs that can be described as either 'public policy' or 'public sector innovation' labs. More often than not, these labs fall under the auspices of government departments or agencies, although what distinguishes a 'public policy' from a 'public sector innovation' team is not at all clear. It is possible to imagine examples of public sector innovation that are not specifically about policy, but in practice the two terms seem to be used interchangeably. Several of the labs identified by Fuller and Lochard (2016) as 'public policy labs' also feature in Nesta's report on public sector i-teams (Puttick et al. 2014) and in an earlier map of government innovation labs (Selloni and Staszowski 2013).

Beyond the confusing nomenclature, there appears to be a number of important characteristics of labs. Schuurman and Tõnurist $(2017,9)$ point to their status as 'change agents', suggesting they are structurally set apart from the rest of the public sector and operate with a large degree of autonomy in setting their targets and working methods $(2017,9)$. This enables them to 'hold disruptive potential' (Tõnurist et al. 2017, 16) by becoming 'dedicated "safe" spaces' (Carstensen and Bason 2012, 5) for experimenting with policy ideas and innovations. Williamson $(2015 b, 4)$ characterises PSI labs as 'ideational institutions' or 'experimental R\&D lab[s] for solving the social and public problems that vex governments', a description that coheres with Nesta's definition of PSI labs as 'structures that use experimental methods to address social and public challenges' (Puttick 2014, 4-6). It adds that they should be ongoing structures rather than 'one-off events, or time-limited projects' (Puttick 2014, 4 see also Kieboom 2014, 13).

While labs are generally regarded as experimental in some sense, they vary significantly in their proximity to executive power. Some are centrally located within the executive branches of government; others sit between multiple government agencies and departments; while others operate as non-governmental organisations that are contracted to work on policy and public sector innovation. The PSI labs identified in Nesta's overview of i-teams also employ quite different methodological approaches, including user-centred design, new analytical techniques in data science, randomised assignment experiments and behavioural insights. What distinguishes organisations as PSI labs in Nesta's view is their use of novel 'experimental methods' (Puttick 2014, 6) rather than any specific approach to innovation. Accordingly, Nesta includes the Behavioural Insights Team (BIT) among the list of 20 PSI labs identified in its i-teams report (Puttick et al. 2014, 8). Tasked with harnessing policy insights from behavioural economics and psychology, BITs have brought social-scientific methods such as randomised control trials into the heart of government and share an important core characteristic of PSI labs in terms of their status as 'change agents' within the public sector (see John 2014, 263-264).

In contrast to Nesta's broad conceptualisation, many other definitions explicitly define PSI labs in terms of their adoption of 'design thinking' practices and collaborative approaches to innovation. For example, La 27e Région's overview of public policy labs 
in EU member states defines PSI labs as 'dedicated teams, structures, or entities focused on designing public policy through innovative methods that involve all stakeholders in the design process' (Fuller and Lochard 2016, 1; emphasis added). BITs are omitted from its list of more than 60 PSI labs presumably because they do not focus sufficiently on '(2014, 21) construct[ing] public policies in an innovative, design-oriented fashion' (Fuller and Lochard 2016, 2; emphasis added). Similarly, Bason and Schneider (2014, 35, emphasis added) argue that PSI labs 'tackle complex public/social problems that more traditional governmental structures fail to resolve, in particular, using design to experiment and propose innovative public services and policies and at the same time reform and change the way government operates'.

Such characterisations reflect 'the omnipresence' (Kieboom 2014, p. 21) of design thinking in the lab field. Although design has long been considered fundamental to policymaking, the type of design thinking espoused by PSI labs originates from the disciplines of industrial, product and service design. Within the policy sciences, design is often conceived as 'an intendedly rational' (Mintrom and Luetjens 2016, 393) and largely linear decision-making process: policy goals are first formulated, possible courses of action are then enumerated and analysed through tools of 'prediction, valuation and measurement', before the most efficient or effective option is selected for implementation (Wagle 2000, 208). In the most idealised mechanistic models, policy scientists argue that policymaking should increasingly resemble a professional scientific rather than political activity in which decisions are objectively determined by evidence about 'what works and why' (Parsons 2002, 46). Policymaking seldom adheres in practice to such a rigidly mechanistic decision model but at the centre of positivist approaches is the hope that policy problems can be reduced to technical problems that can be rationally solved through greater precision in diagnosing problems and more rigorous understanding of causal linkages (Head 2008). Quantifiable, statistically verifiable knowledge is the principal currency within this 'knowledge as power' (Parsons 2002, 46) model of policymaking, which views the solution to the complexity of today's policy challenges as the development of more sophisticated and rigorous analytical techniques (Wagle 2000). Viewed from this (idealised) perspective, policy design constitutes an empirically driven decision model that is underpinned by the values of precision and objectivity.

Proponents of 'design thinking', by contrast, argue that policy design should equally be guided by the values of 'empathy' and 'curiosity', alongside 'rationality' (Torjman 2012, 19). It is seen as a more 'pragmatic yet speculative approach' (O'Rafferty et al. 2016, 3573) to generating policy-relevant knowledge via an evolving, iterative and 'self-correcting' decision-making process in which prototyping is central (Torjman 2012, 10). The modes of reasoning involved follow a situated and abductive rather than deductive logic that depends upon designers deeply immersing themselves in thickly experiential policy contexts (see also Bailey and Lloyd 2016; Kimbell 2016). Within this paradigm, it is pragmatic agreement between designers and 'non-expert' users about the desirability and practicality of solutions - rather than statistical validity - that determines the evidence base for decisionmaking. Accordingly, the 'legitimacy' of decisions is more a function of the 'depth and breadth of involvement' (O'Rafferty et al. 2016, 3586) of citizens and other end users in the design process than the rigour of the analytical techniques. This participatory emphasis is reflected in the professed focus of many PSI labs on 'crafting new solutions with people, not just for them' (Carstensen and Bason 2012, 6), which is thought to not only increase the probability of finding transformative solutions (Torjman 2012) but also add democratic legitimacy to any enacted results. Any such legitimacy would however depend on the representatives of 'who actually participates in the design thinking process' (Mintrom and 
Luetjens 2016, 393), which is seldom transparent in the actual practice of PSI labs. To this extent, proponents frame 'design thinking' as potentially involving 'an entirely different decision-making model for policy' (Bailey and Lloyd 2016, 3624); one that permits 'emotion and intuition' as valid bases for determining viable options (Bason 2013, x). We return to this potential tension between the 'designerly' approach of PSI labs and positivist paradigms of evidence-based policymaking towards the end of this paper.

\section{Sampling PSI labs}

PSI labs, as we have seen, are loosely conceptualised within the literature notwithstanding the prominence of design thinking in many descriptions. In order to further clarify and distinguish PSI labs from other actors in the policy process, we sought to map the characteristics of PSI labs along several key dimensions, including: their relationship to government, the principal approaches and methods they use, and the stages of the 'policy cycle' they are engaged in. They speed at which PSI labs are being established coupled with the conceptual indeterminacy surrounding their definition makes choosing a sample of PSI labs particularly challenging. We approached this problem by reviewing the lists of labs identified in previous review articles, working papers and maps of the field and narrowing this to only those labs that were referenced in at least two sources. Searches of Google Scholar for publications on the following search terms-public policy lab(s); policy design lab(s); public sector innovation lab(s); public innovation lab(s); and government innovation lab(s) - revealed three academic working papers (Gryszkiewicz et al. 2016; Tõnurist et al. 2015; Williamson 2015b) and two journal articles (Tõnurist et al. 2017; Williamson 2015a) on the emergence of PSI labs that included lists of multiple PSI labs. A similar number of overviews and maps produced by practitioner organisations within the field were also uncovered using this search strategy (Acevedo and Dassen 2016; Fuller and Lochard 2016; Puttick et al. 2014; Selloni and Staszowski 2013; Torjman 2012), along with several ethnographies of individual PSI labs (Bailey and Lloyd 2016; Carstensen and Bason 2012; Kimbell 2015) that were already listed in the academic and practitioner overviews. After cross-referencing these inventories, we identified 23 labs that were cited in at least two different sources (see Table 1). We did not follow some previous reviews (e.g. Fuller and Lochard 2016) in including units based on their pursuit of a design thinking approach to policy but remained agnostic about their underlying methodologies and approaches. BITs were omitted from our sample simply because they were only referenced in one report (Puttick et al. 2014).

The majority of PSI labs listed in Table 1 were still active in December 2016, although three had been decommissioned:

- DesignGov An 18-month pilot initiative of the Australian Public Service to test the application of design-led approaches to inter-agency problems that operated until December 2013 (Roberts 2014).

- The Studio A collective of planners, architects, area managers and community developers that came together from late 2010 to April 2014 to grow innovation capacity within Dublin City Council through the pursuit of collaborative, co-creative approaches (The Studio DCC 2014).

- The Helsinki Design Lab Established by Sitra, Finland's innovation fund, in 1968 as a summer school for young designers, engineers and architects to rethink the role of design as a more socially oriented practice, it was reconvened 40 years later as an 


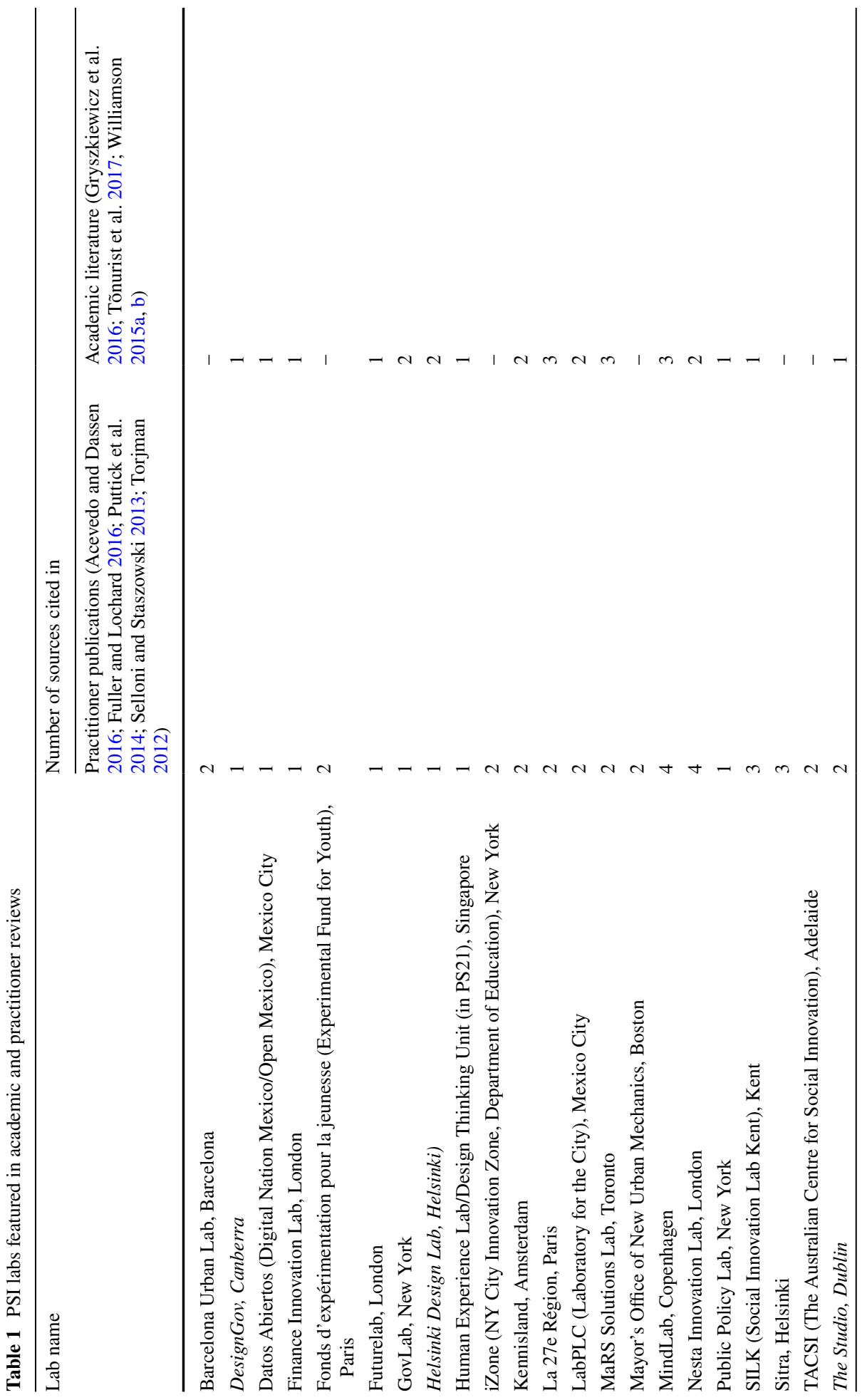




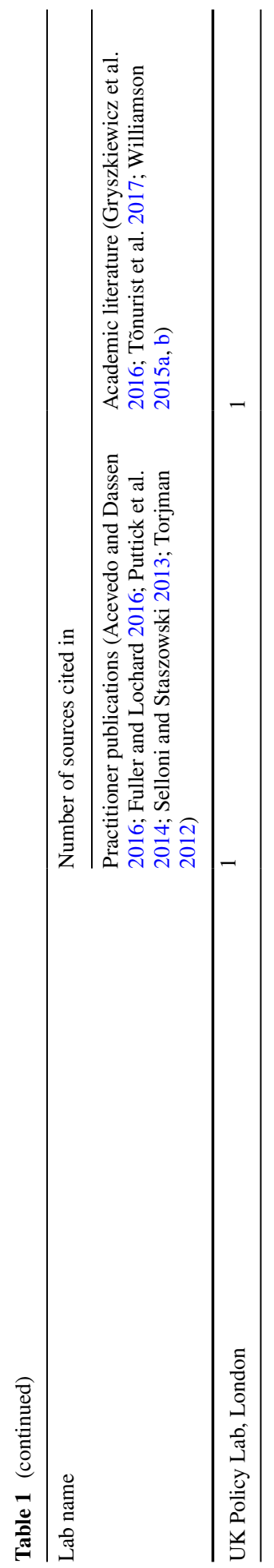


organisation purposed with applying strategic design practices to the problems facing governments. This iteration lasted until June 2013 (Helsinki Design Lab 2013), although Sitra has maintained its commitment to applying design thinking to policy challenges through other programmes.

These examples illustrate how PSI labs are often 'themselves experimental initiatives' (Fuller and Lochard 2016, 1) that are vulnerable to the loss of political patronage and potential for conflict with more established organisations (Tõnurist et al. 2017, 20).

Next, we analyse the location of PSI labs in relation to government through drawing on the policy sciences literature on policy advisory system (PAS) and comparing the situation of PSI labs to other policy actors. This is followed by a consideration of the various approaches they rely upon (e.g. evidence-based or design-led) and the type of policyrelated activities PSI labs undertake. In doing so, we draw on information gathered from each lab's own website and reports, previous overviews and ethnographies of individual labs and projects (Carstensen and Bason 2012; e.g. Kimbell 2015, 2016). We limited the analysis to the 20 PSI labs still active in December 2016, for which information was publicly available on websites and in reports. To explore the characteristics of labs in relation to other policymaking entities and activities, we have applied explanatory models from the policy sciences literature.

\section{PSI labs' relations to governments}

Locational models of PAS systems typically map policy actors along two dimensions, whether they are: located inside or outside of government and subject to high or low government control. Veselý (2013) distinguishes between four different types of actors: proximate internal actors who are part of the government sector and subject to high government control (e.g. central public administration organisations); peripheral internal actors who are part of the government sector but subject to low government control (e.g. bureaux of statistics); proximate external actors who are not part of the government sector but are linked to it via legal obligations (e.g. policy consultants); and peripheral external actors such as business associations, trade unions and other interest groups subject to weak government control.

Locational models are underpinned by the assumption that actors more proximate to executive power are able to exert more influence over policymaking processes (Craft and Howlett 2012). However, proponents of PSI labs have contested the value of proximity to government. Mulgan (2014) describes this as the radical's dilemma: working at a distance from government may better enable PSI labs to develop more frame-breaking alternatives to the status quo, at the risk of being ignored and marginalised; while working more centrally within government may enable PSI labs to more directly influence the levers of power but at the risk of being co-opted and shifted from radical to incremental change. The 'insider-outsider' logic (Fraussen and Halpin 2017, 105) of locational models can also struggle to capture emerging policy actors that resist easy compartmentalisation as either within or outside of government (see Craft and Howlett 2012, 83-85). PSI labs are a case in point given their semi-autonomous status within the public sector.

Here we focus on two aspects of PSI labs' relations to governments: (1) the extent to which they are funded by government; and (2) whether they are subject to direct oversight by government. From the available information, we can clearly identify a continuum in 
Table 2 PSI labs by dimensions of relationship to government

\begin{tabular}{|c|c|c|c|}
\hline \multirow{2}{*}{$\begin{array}{l}\text { Direct government } \\
\text { oversight }\end{array}$} & \multicolumn{3}{|c|}{ Level of government control over funding } \\
\hline & No government funding & Partly funded & Wholly funded \\
\hline Yes & & $\begin{array}{l}\text { Government-led labs } \\
\text { Fonds d'expérimentation pour } \\
\text { la jeunesse } \\
\text { Mayor's Office of New Urban } \\
\text { Mechanics } \\
\text { LabPLC } \\
\text { La 27e Région } \\
\text { MindLab } \\
\text { Sitra }\end{array}$ & $\begin{array}{l}\text { Government-controlled } \\
\text { labs } \\
\text { Barcelona Urban Lab } \\
\text { Datos Abiertos } \\
\text { Human Experience } \\
\text { Lab/Design Thinking } \\
\text { Unit } \\
\text { iZone } \\
\text { Policy Lab (UK) } \\
\text { SILK }\end{array}$ \\
\hline No & $\begin{array}{l}\text { Independently run labs } \\
\text { Finance Innovation Lab } \\
\text { MaRS Solutions Lab } \\
\text { GovLab }\end{array}$ & $\begin{array}{l}\text { Government-enabled labs } \\
\text { Futurelab } \\
\text { Kennisland } \\
\text { Nesta Innovation Lab } \\
\text { Public Policy Lab } \\
\text { TACSI }\end{array}$ & \\
\hline
\end{tabular}

relation to funding, with some labs wholly government-funded while others receive some government funding, and yet others, none at all. This analysis was helped in large part by the financial transparency displayed in Nesta's 'i-teams' report and on individual lab websites such as that of GovLab. There is, however, little publicly available information on the level of government oversight of individual PSI labs. Consequently, we have used their ownership structure (government, mixed or independent) as a proxy for the level of government oversight, combined with data on their sources of funding, in order to determine each lab's relationship to government.

Table 2 shows considerable variation in the structure of PSI labs along these two dimensions. Although the majority (12) are subject to some level of oversight by government, only six are entirely government-funded (Barcelona Urban Lab, Datos Abiertos, The Human Experience Lab, iZone, Policy Lab UK and SILK). These six labs are also overseen by governments, and we therefore describe them as government-controlled labs. At the opposite end of the spectrum are three independently run labs (Finance Innovation Lab, MaRS Solutions Lab, GovLab) that neither receive direct government funding nor are subject to any government oversight of their operations. These labs are most analogous to think tanks within traditional locational models- 'independent, non-interest based, non-profit organizations that produce and principally rely on expertise and ideas to obtain support and influence the policy-making process' (Fraussen and Halpin 2017, 106). Within the literature on PAS, think tanks have tended to be viewed through the prism of evidencebased policymaking (Craft and Howlett 2013, 194). Trading on a reputation for intellectual integrity, they seek to influence policymaking by translating research into 'useable' policy knowledge (Fraussen and Halpin 2017, 114).

In between government-controlled and independently run labs are two borderland categories that best exemplify the characterisation of PSI labs as new kinds of 'intermediary' (Williamson 2015a, 261) knowledge actors. On the one side are government-led labs whose operations are subject to direct government oversight (for example, Sitra reports to the Finnish Parliament and its Board of Directors includes senior civil servants) and rely partially on government funding. Examples include MindLab and La 27e Région. On 
the other side are labs that are also partly government-funded but subject to little or no direct government oversight (other than contractual requirements stipulated in funding agreements), which we term government-enabled labs. These labs approximate the position of commissioned consultants within PAS in the sense that they form part of the 'external' professional policy analysis community competing for government commissions and research contracts (Howlett and Migone 2013, 242). What distinguishes them from large consultancy firms may be little more than the types of 'knowledge' and methodological expertise they are selling to governments, which we consider below.

\section{PSI labs' approaches and methods}

It is commonly asserted that PSI labs provide methodological expertise and skills 'beyond what most trained civil servants usually possess' (Carstensen and Bason 2012, 5) and that they help to bring knowledge and practices from other fields 'into the heart of public service' (Puttick et al. 2014, 5). But what specific forms of knowledge and expertise do PSI labs offer governments and the public sector? Drawing on their own website descriptions as well as other analyses and insider ethnographies, we identified four predominant approaches taken in terms of the methods, tools and techniques employed by PSI labs:

1. Design-led labs Emphasise the application of design thinking to policy and prioritise 'user-centred' methods such as ethnography, visualisation techniques and collaboration with citizens and other stakeholders to clarify problem definitions and co-create solutions (see Bailey and Lloyd 2016; Mintrom and Luetjens 2016).

2. Open government/data labs Employ innovative approaches in data analytics such as applying new digital and web-based tools to open up and interrogate public data. While they may share an emphasis with design-led labs on participatory methods, 'open government' labs can be distinguished by their focus on increasing the accessibility of government data, and drawing on expertise from diverse participants to run and apply data analytics, for example through the organisation of hackathons.

3. Evidence-based labs Are those that focus on the application of rigorous evaluation techniques, principally randomised controlled trials (RCTs) and an adherence to the idea of evidence-based policy.

4. The label mixed methods were used for labs that showed no preference for one particular set of approaches.

Table 3 maps the dominant methodological approach of each of the 20 PSI labs along these four categories and grouped into our earlier typology of independently run, government-enabled, government-led and government-controlled labs. Where there were discrepancies between descriptions or classifications of a PSI lab, we privileged information provided by the lab's own staff to determine a dominant approach. For instance, while much academic analysis of the UK Policy Lab has focused on its application of design to policymaking (Bailey and Lloyd 2016; Kimbell 2015), its director describes its use of 'three forces - digital, data and design - that promise to bridge the gap between citizens and the state' (Siodmok 2014, 26). Our analysis of publicly available examples of UK Policy Lab projects confirms that it combines elements of design thinking, evidence-based policy and open government (Cabinet Office n.d.). 
Table 3 PSI labs approaches and types

\begin{tabular}{|c|c|c|c|c|}
\hline & $\begin{array}{l}\text { Independently } \\
\text { run }\end{array}$ & $\begin{array}{l}\text { Government- } \\
\text { enabled }\end{array}$ & Government-led & Government-controlled \\
\hline Design-led & & $\begin{array}{l}\text { Futurelab } \\
\text { Kennisland } \\
\text { Public Policy } \\
\text { Lab } \\
\text { TACSI }\end{array}$ & $\begin{array}{l}\text { Mayor's Office } \\
\text { of New Urban } \\
\text { Mechanics } \\
\text { La 27e Région } \\
\text { MindLab }\end{array}$ & $\begin{array}{l}\text { The Human Experience } \\
\text { Lab/Design Thinking } \\
\text { Unit } \\
\text { SILK }\end{array}$ \\
\hline $\begin{array}{l}\text { Open government/ } \\
\text { data }\end{array}$ & GovLab & $\begin{array}{l}\text { Nesta Innova- } \\
\text { tion Lab }\end{array}$ & & $\begin{array}{l}\text { Barcelona Urban Lab } \\
\text { Datos Abiertos }\end{array}$ \\
\hline Evidence-based & & & $\begin{array}{l}\text { Fonds } \\
\text { d'experimentation } \\
\text { pour la jeunesse }\end{array}$ & \\
\hline Mixed methods & $\begin{array}{l}\text { Finance Innova- } \\
\text { tion Lab } \\
\text { MaRS Solutions } \\
\text { Lab }\end{array}$ & & $\begin{array}{l}\text { LabPLC } \\
\text { Sitra }\end{array}$ & $\begin{array}{l}\text { iZone } \\
\text { Policy Lab (UK) }\end{array}$ \\
\hline
\end{tabular}

Almost half of the labs can be classified as design-led, with design thinking particularly prevalent among labs that have been established within public administrations or funded by governments to work on public sector innovation. MindLab exemplifies this type of lab, with its focus on human-centred design and user-centred innovation in public service delivery and reform.

Four PSI labs in our sample were categorised as open government/data labs, an approach epitomised by New York University's GovLab belief that 'increased availability and use of data, new ways to leverage the capacity, intelligence, and expertise of people in the problem-solving process, combined with new advances in technology and science can transform governance' (GovLab 2016). The open government agenda appears to be a strong focus of PSI labs in Latin American countries, with these reportedly focusing more on citizen participation and open data than on experimentation or evaluation (Acevedo and Dassen 2016, 10).

We identified only one example of a PSI lab that could be clearly classified as predominantly evidence-based: Fonds d'expérimentation pour la jeunesse. A French Government established fund aiming to improve young people's educational achievement and social and professional integration, it is characterised by its use of rigorous evaluation methods, such as RCTs, and its objective to 'inspire evidence-based policies related to youth' (Valdenaire, cited in Puttick et al. 2014, 29).

Another four labs fell into our mixed methods category, although both the Finance Innovation Lab and the MaRS Solutions Lab include 'design thinking' within the suite of approaches they employ.

\section{PSI labs and the policy process}

PSI labs are a response to the cross-cutting nature of contemporary policy and social challenges. But how much of what PSI labs do actually involves producing policy-relevant knowledge about problems requiring sophisticated and inter-sectoral solutions? And at 
what stages of the policy process are PSI labs involved in innovating policy and public sector reforms? These are fundamental questions given claims about the redundancy of 'existing ways of doing things in the making of government policy' (Kimbell 2016, 3606) and the urgency of 'smarter solutions in increasingly turbulent, complex and interdependent societal and human settings' (Bason 2013, ix). A comprehensive answer would require detailed case studies of the activities of individual PSI labs over a sustained period, including assessing the impact of their policy proposals and evaluating the outcomes of any implemented initiatives. As a starting point, we have assembled data about some key projects of individual PSI labs and the types of policy-related activities they mainly focus on. Drawing on the commonly identified stages of the 'policy cycle' (Howlett et al. 2009), we classified the activities of PSI labs according to the following types of policy-relevant activity:

1. Identifying problems and informing the policy agenda (e.g. through research and/or data generation, analysis or dissemination).

2. Generating proposals and identifying potential solutions (e.g. through ideation, crowdsourcing, researching options).

3. Testing solutions (e.g. prototyping, piloting).

4. Decision-making (e.g. choosing solution/course of action, determining/producing policy).

5. Implementing policy instrument(s) and/or scaling solutions.

6. Monitoring and evaluating.

There was enough publicly available English-language information about the activities of all labs in our sample to categorise them in this way, expect for LabPLC. The most common types of policy-related activity we identified were generating and testing solutions-16 and 17 out of 19 PSI labs, respectively, had demonstrated their involvement in these two kinds of activities - along with problem definition and analysis, in which numerous labs engaged. We found fewer examples (5) of labs engaged in implementation and/or scaling activities, and barely any instances of labs being involved in policy decision-making. Exceptions were MindLab's work with the Danish Ministry of Employment to reform youth employment services, which moved from generating new ideas and co-designing initiatives to recommending specific legislative changes required for policy goals (Christiansen 2016), and Sitra, the world's oldest public innovation agency, which has helped to scale new health services and programmes in Finland including a health service voucher scheme adopted by over 100 municipalities (Puttick et al. 2014, 29).

There is a degree of correspondence between the approaches that these labs take and the aspect of the policy process they focus on. Given that nearly half of the sampled labs were design-led and a number of those classified as mixed also did designerly work, it is not surprising that generating and testing solutions was the most commonly identified activity. Their activities are generally closer to service design or capability building than policy design, especially among the design-led labs. The first programme developed by La 27e Région (2017), for instance, involves a multidisciplinary team immersing themselves in residence within a public facility or service to observe current practices and experiences, rapidly test different options and ultimately propose concrete improvements. TACSI has similarly largely focused on programme and service design activities, although it has also prototyped policy solutions as part of its philanthropically funded 'Innovation Age' project (Burkett 2016). 
To some extent, PSI labs' lack of engagement with traditional policymaking processes may be intentional, as they seek to offer alternative ways of addressing public problems. There are few examples of PSI labs working on major policy reforms, such as changes to social security legislation, rather than improvements to the way existing services and policies are delivered and enacted (Carstensen and Bason 2012, 17; see, for example, Kimbell 2015). Other than helping to make government services more accessible, efficient and streamlined, it is unclear whether PSI labs are helping to address policy problems at a more structural level.

\section{Discussion: PSI labs, design thinking and policy systems}

The 'problem' of public sector innovation has inspired many developments in public policy and public management, including the spread of NPM ideas and associated trends towards commissioning consultants to study and provide policy-relevant knowledge. Our analysis of the conceptualisation of PSI labs and the characteristics of 20 examples indicates that what differentiates PSI labs from other kinds of knowledge actors is their embrace of designerly methods inspired by the disciplines of industrial, product and service design. How this new design thinking fits within the 'knowledge frames' (Adams 2004, 31) and standards of expertise embedded in the ontologies of paradigms of evidence-based policy and experimentation in policy design (Parsons 2002; Sabel and Zeitlin 2010; Stoker and John 2009) remains unclear.

The role of 'evidence' in policymaking receives significant attention, as policymakers aspire to show that their decisions are based upon evidentiary facts rather than ideology or partisan beliefs. Policy development based on social-scientific evidence about what works is prescribed by positivist-oriented policy scientists as the way to make and do policy. The spread of BITs across government departments in the UK, Australia and elsewhere (John 2014) is one manifestation of this positivist desire to bring order and control to the 'fuzzy and messy realities' (Head 2008, 3) of policy through the discovery of 'hard facts'. The presumption is that better evidence, achieved through more precise and rigorous analytical techniques, will lead to more effective policies while depoliticising policymaking by elevating it to a science (Wagle 2000). This rendering of policymaking as a neutral and objectively determined decision-making model is dismissed by critics as a naively rationalist, 'technocratic wish in a political world' (Lewis et al. 2003) that presumes an all too linear relationship between evidence and policymaking and an untenable distinction between (policy) facts and (political) values. Political and technical rationalities are in reality frequently blended (Baekkeskov 2016, 397) and the evidence that policymakers choose to draw on is in itself a value-laden decision, where what is ignored is as important as what is chosen (Clarence 2002, 5). Establishing policymaking upon a heavily 'evidence-based' orientation brings with it the risk that the domain of policy-relevant knowledge will be colonised by policy experts schooled in producing the sort of quantifiable, social-scientific knowledge that is the 'modern currency of public policy' (Adams 2004, 30). This is reflected in the greater esteem attached to quantitative disciplines such as health economics and risk analysis compared to more hermeneutic and interpretative disciplines such as history and cultural sociology (Head 2008).

The emerging literature on PSI labs rarely reflects on how the 'designerly ways of knowing' (Bailey and Lloyd 2016, 3626) and interpretive thinking styles (Bason 2013, x) espoused by many PSI labs fit within the instrumental rationality of positivist 
framings of 'evidence-based' policymaking. Overviews and practice guides rather simplistically try to position design thinking 'within the wider context of efforts to bring innovative methods to the public sector, such as behavioural insights or other evidencebased approaches' (Centre for Public Impact 2016, 3 also Fuller and Lochard 2016, 1). It may be that some aspects of design-led approaches can be incorporated in a way that does not disrupt 'the rational mission of "evidence-based" policy' (Head 2008, 9). For example, Mintrom and Luetjens' (2016) description of design thinking suggests a rather minimal role for a designerly approach, seeing it as merely an extra source of stakeholder engagement and glossing over the creativity and divergence aspects which are fundamental to it. Yet design thinking problematizes scientific approaches to policy design by challenging conventional understandings of expertise and evidence. Participatory, user-centred approaches may excel in producing ethnographically informed insights and in collaboratively generating ideas that have 'buy in' from stakeholders. But they seldom produce the kind of quantifiable, 'the size of the effect of A on B is', evidence demanded by positivist models (Parsons 2002, 46). In her ethnography of the UK Policy Lab, Kimbell $(2015,31)$ shows how the visual and creative methods of design open up policymaking to more diverse inputs and forms of expertise. They bring into view the worlds of the people affected by policy issues and demand that project teams are accountable to this non-expert evidence and not just the insights of policy or technical specialists (Kimbell 2016, 3616). Bailey and Lloyd similarly observe an epistemological tension between the Policy Lab's creative approaches to knowledge production and mainstream policymaking ways of knowing that rely on managing knowledge in specific ways. The former are seen as problematic because they are not considered 'sufficiently representative, quantifiable, or reliable' (Bailey and Lloyd 2016, 3626).

As Rebolledo (2016, 43) argues: 'design [thinking] may offer a fundamental reinvention of the art and craft of policymaking' that reorients policymaking in a more post-positivist direction away from the terra firma of scientific rigour and independence and towards a model that incorporates a more diversified range of values, norms and sources of evidence (Wagle 2000). Along with scholars such as Tenbensel (2006) and Head $(2008,4,9)$ has called for policy scientists to embrace a broader understanding of policy-relevant knowledge that can acknowledge the diversity of 'evidence' to be found in networked policy environments and through community engagement. It may be that this is where PSI labs can have the greatest impact: harvesting the array of knowledge(s) found in diverse places and packaging these into usable forms of policy knowledge. Further research and critical reflection is nonetheless needed on whether the " quick and dirty” methodologies' (Tõnurist et al. 2017, 20) of PSI labs can deliver implementable solutions to problems that are structurally complex and necessitate interconnected solutions.

In summary, the PSI labs featured in this paper are predominantly engaged in service design work. This underscores the strength of design thinking approaches in practice but also points to its limitations in regard to more structural and systemic challenges. While local community issues may be amenable to analysis without tertiary education in sociology, economics or political science, the methodic practices of design may start to crumble when they are extended to system-wide challenges and understanding the complicated linkages between the market and the state (Chen et al. 2016, 3). Furthermore, although involving citizens and other end users in collectively framing problems and ideating solutions may be an important normative ideal, there is little evidence that demonstrates whether this produces better policies and public service innovations, as 
highlighted in a recent systematic review of studies on co-creation and co-production (Voorberg et al. 2015, 1341).

This paper has established some important starting points for further examinations of PSI labs. We have found an array of different relationships to government, a variety of approaches - although with design thinking clearly favoured by those labs and overviews included in our analysis - and a focus on identifying and testing proposals and solutions as a way of contributing to the policy process. Choosing a different sample of labs using other criteria might reveal other classifications of PSI labs, but this sample nonetheless represents some important characteristics of several well-known and longestablished labs. We have also raised a number of questions about the role of PSI labs as new actors in PAS and whether they are capable of addressing larger scale policy design problems. There is clearly a need for further research to explore these, and other, questions about the interactions and impacts of PSI labs in relation to policy processes and outcomes. As it stands, we can say little about whether PSI labs might be able to go beyond identifying problems and testing potential solutions in service design to tackling large and systemic issues. More in-depth study is required before we can make claims about whether PSI labs' proposals are implemented, whether they are improving policy effectiveness, whether they are really a distinctly new type of actor, or whether they are changing the landscape of PAS. Given the rise of PSI labs, these are important questions for future research.

\section{References}

Acevedo, S., \& Dassen, N. (2016). Innovation for better management: The contribution of public innovation labs. Washington, D.C.: Inter-American Development Bank.

Adams, D. (2004). Usable knowledge in public policy. Australian Journal of Public Administration, 63(1), $29-42$.

Baekkeskov, E. (2016). Explaining science-led policy-making: Pandemic deaths, epistemic deliberation and ideational trajectories. Policy Sciences, 49(4), 395-419.

Bailey, J., \& Lloyd, P. (2016). The introduction of design to policymaking: Policy Lab and the UK government. In P. Lloyd \& E. Bohemia (Eds.), Proceeceedings of DRS 2016: design + research + society (pp. 3619-3634). Brighton: Design Research Society.

Bason, C. (2013). Discovering co-production by design. In E. Manzini \& E. Staszowski (Eds.), Public and collaborative: Exploring the intersections of design, social innovation and public policy (pp. viii-xvi). New York: DESIS Network.

Bason, C., \& Schneider, A. (2014). Public design in global perspective: Empirical trends. In C. Bason (Ed.), Design for policy (pp. 23-40). Farnham, Surrey: Routledge.

Burkett, I. (2016). Could prototyping reduce risks and increase the chance of success in policymaking? Presented at the Tacsifest, Melbourne.

Carstensen, H. V., \& Bason, C. (2012). Powering collaborative policy innovation: Can innovation labs help? The Innovation Journal, 17(1), 2-26.

Centre for Public Impact. (2016). Briefing bulletin: design for policy and public services. Centre for Public Impact. https://www.centreforpublicimpact.org/briefing-bulletin-design-for-policy-and-public-servi ces/. Accessed November 3, 2016.

Chen, D.-S., Lu-Lin, C., Hummels, C., \& Koskinen, I. (2016). Social design: An introduction. International Journal of Design, 10(1), 1-5.

Christiansen, J. (2016). Embedding design: Towards cultural change in government. In B. Mager (Ed.), Service design impact report: public sector (pp. 48-59). Köln: Service Design Network.

Clarence, E. (2002). Technocracy reinvented: The new evidence based policy movement. Public Policy and Administration, 17(3), 1-11.

Considine, M., \& Lewis, J. M. (2003). Bureaucracy, network, or enterprise? Comparing models of governance in Australia, Britain, the Netherlands, and New Zealand. Public Administration Review, 63(2), $131-140$. 
Craft, J., \& Howlett, M. (2012). Policy formulation, governance shifts and policy influence: Location and content in policy advisory systems. Journal of Public Policy, 32(02), 79-98.

Craft, J., \& Howlett, M. (2013). The dual dynamics of policy advisory systems: The impact of externalization and politicization on policy advice. Policy and Society, 32(3), 187-197.

Fraussen, B., \& Halpin, D. (2017). Think tanks and strategic policy-making: The contribution of think tanks to policy advisory systems. Policy Sciences, 50(1), 105-124.

Fuller, M., \& Lochard, A. (2016). Public policy labs in European Union member states. Luxembourg: European Union.

GovLab. (2016). Who we are? The Gov Lab. http://www.thegovlab.org/about.html. Accessed November 11, 2016

Gryszkiewicz, L., Lykourentzou, I., \& Toivonen, T. (2016). Innovation labs: leveraging openness for radical innovation? (SSRN Scholarly Paper No. ID 2556692). Rochester, NY: Social Science Research Network. http://papers.ssrn.com/abstract=2556692. Accessed September 28, 2016.

Hart, P. 't, \& Vromen, A. (2008). A new era for think tanks in public policy? International trends, Australian realities. Australian Journal of Public Administration, 67(2), 135-148.

Head, B. W. (2008). Three lenses of evidence-based policy. Australian Journal of Public Administration, $67(1), 1-11$.

Helsinki Design Lab. (2013). HDL closing in 2013. http://www.helsinkidesignlab.org/moimoi. Accessed May 12, 2017.

Hood, C. (1991). A public management for all seasons? Public Administration, 69(1), 3-19.

Howlett, M., \& Migone, A. (2013). Policy advice through the market: The role of external consultants in contemporary policy advisory systems. Policy and Society, 32(3), 241-254.

Howlett, M., Ramesh, M., \& Perl, A. (2009). Studying public policy: Policy cycles and policy subsystems. Oxford: Oxford University Press.

Jenson, J., \& Harrisson, D. (2013). Social innovation research in the European Union: Approaches, findings and future directions. Luxembourg: European Union.

John, P. (2014). Policy entrepreneurship in UK central government: The behavioural insights team and the use of randomized controlled trials. Public Policy and Administration, 29(3), 257-267.

Kieboom, M. (2014). Lab matters: Challenging the practice of social innovation laboratories. Amsterdam: Kennisland.

Kimbell, L. (2015). Applying design approaches to policy making: Discovering policy lab. Brighton: University of Brighton.

Kimbell, L. (2016). Design in the time of policy problems. In P. Lloyd \& E. Bohemia (Eds.), Proceedings of DRS 2016: Design + research + society (pp. 3605-3618). Brighton: Design Research Society.

La 27e Région. (2017). Territories in residence. La 27e Région. http://www.la27eregion.fr/en/residence/. Accessed February 22, 2017.

Lewis, J. M., Lin, V., \& Gibson, B. (2003). Evidence-based policy: A technocratic wish in a political world. Evidence-based health policy: Problems and possibilities (pp. 250-259). Melbourne: Oxford University Press.

Mintrom, M., \& Luetjens, J. (2016). Design thinking in policymaking processes: Opportunities and challenges. Australian Journal of Public Administration, 75(3), 391-402.

Mulgan, G. (2014). The radical's dilemma: An overview of the practice and prospects of Social and Public Labs. Social and public labs. https://www.nesta.org.uk/sites/default/files/social_and_publi c_labs_-_and_the_radicals_dilemma.pdf. Accessed March 7, 2017.

O'Rafferty, S., de Eyto, A., \& Lewis, H. J. (2016). Open practices: Lessons from co-design of public services for behaviour change. In P. Lloyd \& E. Bohemia (Eds.), Proceedings of DRS 2016: Design + research + society (pp. 3573-3590). Brighton: Design Research Society.

Osborne, D., \& Gaebler, T. (1992). Reinventing government: How the entrepreneurial spirit is transforming government. Reading Mass: Adison Wesley Public Comp.

Parsons, W. (2002). From muddling through to muddling up-Evidence based policy making and the modernisation of British government. Public Policy and Administration, 17(3), 43-60.

Pollitt, C., \& Hupe, P. (2011). Talking about government: The role of magic concepts. Public Management Review, 13(5), 641-658.

Potts, J., \& Kastelle, T. (2010). Public sector innovation research: What's next? Innovation, 12(2), 122-137.

Public Policy Forum. (2013). Changes labs and government in Canada. Ottawa: Canada's Public Policy Forum.

Puttick, R. (2014). Innovation teams and labs: A practice guide. London: NESTA. http://www.nesta.org. uk/publications/innovation-teams-and-labs-practice-guide. Accessed October 12, 2016. 
Puttick, R., Baeck, P., \& Colligan, P. (2014). I-Teams: The teams and funds making innovation happen in governments around the world. London: Nesta and Bloomberg Philanthropies.

Rebolledo, N. (2016). The value of service design in policy making. In B. Mager (Ed.), Service design impact report: Public sector (pp. 40-46). Köln: Service Design Network.

Roberts, A. (2014). Public sector innovation in the Australian public service. Public Manager, 43(1), 20-23.

Sabel, C. F., \& Zeitlin, J. (2010). Experimentalist governance in the European Union: Towards a new architecture. Oxford: Oxford University Press on Demand.

Saint-Martin, D. (2001). How the reinventing government movement in public administration was exported from the US to other countries. International Journal of Public Administration, 24(6), 573-604.

Schuurman, D., \& Tõnurist, P. (2017). Innovation in the public sector: Exploring the characteristics and potential of living labs and innovation labs. Technology Innovation Management Review, 7(1), 7-14.

Selloni, D., \& Staszowski, E. (2013). Gov innovation labs constellation 1.0. New York: PARSONS DESIS LAB. http://nyc.pubcollab.org/files/Gov_Innovation_Labs-Constellation_1.0.pdf. Accessed December 22, 2016.

Siodmok, A. (2014). Designer policies. RSA Journal, 4, 24-29.

Slow Research Lab. (2016). http://slowlab.net. Accessed December 22, 2016.

Stoker, G., \& John, P. (2009). Design experiments: engaging policy makers in the search for evidence about what works. Political Studies, 57(2), 356-373.

Tenbensel, T. (2006). Policy knowledge for policy work. In H. K. Colebatch (Ed.), The work of policy: An international survey (pp. 199-215). Lanham: Rowman \& Littlefield.

The Studio DCC. (2014). Goodbye for now! https://dccstudio.wordpress.com/2014/04/16/goodbye-fornow/. Accessed May 12, 2017.

Thompson, J. R., \& Ingraham, P. W. (1996). The reinvention game. Public Administration Review, 56(3), 291-298.

Tõnurist, P., Kattel, R., \& Lember, V. (2015). Discovering innovation labs in the public sector (No. 61). Norway: The Other Canon Foundation. http://hum.ttu.ee/wp/paper61.pdf. Accessed October $11,2016$.

Tõnurist, P., Kattel, R., \& Lember, V. (2017). Innovation labs in the public sector: What they are and what they do? Public Management Review. https://doi.org/10.1080/14719037.2017.1287939.

Torjman, L. (2012). Labs: Designing the future. Ontario: MaRS Discovery District.

Veselỳ, A. (2013). Externalization of policy advice: Theory, methodology and evidence. Policy and Society, 32(3), 199-209.

Voorberg, W. H., Bekkers, V. J., \& Tummers, L. G. (2015). A systematic review of co-creation and co-production: Embarking on the social innovation journey. Public Management Review, 17(9), 1333-1357.

Wagle, U. (2000). The policy science of democracy: The issues of methodology and citizen participation. Policy Sciences, 33(2), 207-223.

Williamson, B. (2015a). Governing methods: Policy innovation labs, design and data science in the digital governance of education. Journal of Educational Administration and History, 47(3), 251-271.

Williamson, B. (2015b). Testing governance: The laboratory lives and methods of policy innovation labs. Stirling: University of Stirling. https://codeactsineducation.wordpress.com/2015/03/30/testing-gover nment/. Accessed October 12, 2016.

Yu, H., \& Robinson, D. G. (2012). The new ambiguity of 'open government' (SSRN Scholarly Paper No. ID 2012489). Rochester, NY: Social Science Research Network. https://papers.ssrn.com/abstract=20124 89. Accessed November 18, 2016. 